
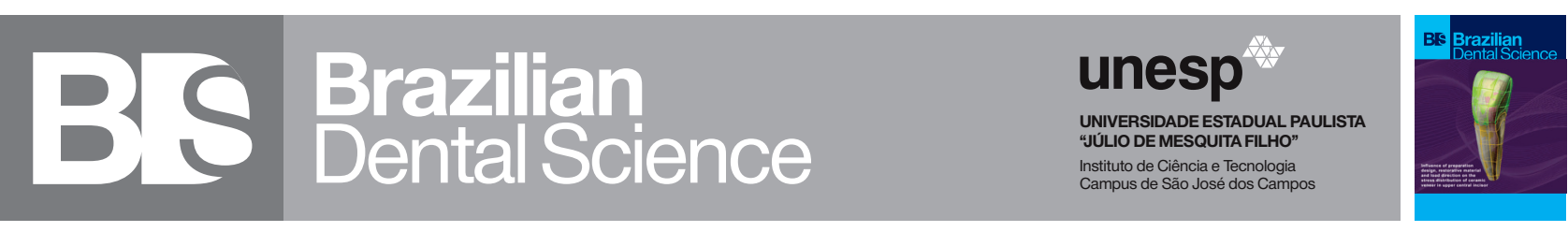

\title{
One-year clinical evaluation of IPS Empress CAD versus polished Celtra Duo ceramic Laminate veneers (randomized controlled clinical trial)
}

Avaliação clínica de um ano de IPS Empress CAD versus laminados de cerâmica Celtra Duo polidos (ensaio clínico randomizado controlado)

Hayat Ibrahim Mahrous EL-BANNA ${ }^{1}$, Mohammed Labib ZAMZAM ${ }^{1}$, Jylan Fouad EL-GUINDY ${ }^{1}$, Ahmed Soliman IDRIS ${ }^{1}$

1 - Faculty of Dentistry, Cairo University, Fixed Prosthodontics, Cairo, Egypt.

\section{ABSTRACT}

Objective: To evaluate fracture resistance and survival rate of IPS Empress CAD versus Polished Celtra Duo ceramic laminate veneers. Material and Methods: Thirty-six ceramic laminate veneers were fabricated for maxillary anterior teeth. The patients were divided into two groups according to the material Group 1(control group) fabricated from IPS Empress CAD laminate veneers and group 2 (intervention group) fabricated from Polished Celtra Duo laminate veneers. Standardized the same preparation with butt joint design and chamfer finish line located supra gingival were performed for all the teeth. The fabrication of the veneers was performed using Cad $\backslash$ Cam (Ceramill motion) machine, with software (Exocad). The veneers surfaces were treated and silanated according to the manufacture instruction of each ceramic and enamel surfaces were etched where total etch adhesive protocol was obeyed using BISCO. Follow up sessions were done every two months up to one year for each patient using dental probe and operator vision to evaluate the fracture, survival rate, marginal adaptation, sensitivity and caries. according to USPHS criteria (United States Public Health Service). This was performed by an experienced, blinded investigator. Results: Fracture resistance, marginal adaptation, retention, caries and sensitivity were evaluated according to the criteria of USPHS and we found there is no significant difference as both groups scaled zero score. Conclusion: Both IPS Empress Cad and Polished Celtra Duo laminate veneers revealed successful clinical performance in terms of fracture resistance, marginal adaptation, retention, and sensitivity after one year follow up period.

\section{KEYWORDS}

Ceramic laminate veneers; IPS Empress CAD; Celtra DUO; Clinical performance.

\section{RESUMO}

Objetivo: Avaliar a resistência à fratura e a taxa de sobrevivência de laminados de cerâmica IPS Empress CAD versus Celtra Duo polidos. Material e Métodos: Trinta e seis facetas cerâmicas laminadas foram confeccionadas para dentes anteriores superiores. Os pacientes foram divididos em dois grupos de acordo com o material Grupo 1 (grupo controle) confeccionado com laminados IPS Empress $\mathrm{CAD}$ e grupo 2 (grupo intervenção) confeccionado com laminados Celtra Duo polidos. A mesma forma de preparo e acabamento de chanfro localizado supra-gengival padronizados foram realizados para todos os dentes. A confecção das facetas foi realizada em máquina Cad $\backslash$ Cam (Ceramill motion), com software (Exocad). As superfícies laminadas foram tratadas e silanizadas de acordo com as instruções do fabricante de cada cerâmica e as superfícies de esmalte foram condicionadas seguindo o protocolo adesivo de condicionamento ácido total com BISCO. Sessões de acompanhamento foram realizadas a cada dois meses durante um ano para cada paciente usando sonda exploradora e visão do operador para avaliar a fratura, taxa de sobrevivência, adaptação marginal, sensibilidade e cárie; de acordo com os critérios USPHS (Serviço de Saúde Pública dos Estados Unidos). Isso foi realizado por um investigador experiente e cego. Resultados: a resistência à fratura, adaptação marginal, retenção, cárie e sensibilidade foram avaliadas de acordo com os critérios da USPHS e não encontramos diferença significativa, pois ambos os grupos escalonaram pontuação zero. Conclusão: As facetas laminadas IPS Empress Cad e Celtra Duo polido revelaram desempenho clínico bem-sucedido em termos de resistência à fratura, adaptação marginal, retenção e sensibilidade após um período de acompanhamento de um ano.

\section{PALAVRAS-CHAVE}

Laminados cerâmicos; IPS Empress CAD; Celtra DUO; Desempenho clínico. 


\section{INTRODUCTION}

$\mathrm{C}$ eramic laminate veneers have become widely a restoration of choice because of their esthetic appeal, biocompatibility and adherence to the concept of minimal invasive dentistry [1].

Long-term success of ceramic laminate veneers could be influenced by several factors, such as type and depth of preparation, type and thickness of the ceramic, type (enamel or dentin) and surface area of the adhesion surface, type of the resin cement and dental adhesive, tooth morphology, as well as functional and parafunctional activities [2].

The most common failure type for laminate veneers was reported to be fractures. The greatest shortcoming of ceramic materials is their low ductility that is an inherent problem yielding to crack formation that can be induced during laboratory and technician adjustments or even during machining especially when used in thin restorations as laminate veneers. Also, polymerization shrinkage of the luting composite may create stress concentrations at the adhesive interface [3-5].

It was found that in case of glass ceramics laminate veneers (feldspathic, leucite based and lithium silicate-based ceramics) fracture of the ceramic is the most frequent reason for failure (44.83\%). The second reason for failure was cracks in the ceramic veneer (27.59\%). Chipping and debonding occurred in 10\% of all failure cases [6].

CELTRA DUO: is a new generation of glass ceramic material enriched with approximately $10 \%$ zirconia by weight, which resulting in zirconia reinforced lithium silicate ceramic (ZLS). The material has a special fine grained and homogeneous structure which provides excellent material quality and consistency, higher load capacity as well as long term reliability. Additionally, the material has outstanding processing characteristics, including easy milling and polishing. After the milling process takes place no additional crystallization step required [7]. The flexural strength of the milled restoration is 210 MPa. After glaze firing the flexural strength is increased to $370 \mathrm{MPa}$ [8].
For the patient's comfort, ceramic restorations should have smooth surface. It is also important for esthetic and biological reasons. So, polishing of ceramic surfaces is mandatory after removal of excess cement or after occlusal adjustments [9].

External marginal adaptation of ceramic veneers, which is defined as "the vertical distance between the finish line of the prepared tooth and the margins of the fabricated veneers" [5] has an important role in the success of any type of restorations[5].

According to Gresnigt et al. [5] who observed decrease in the marginal adaptation of leucite based laminate veneers which recorded after a follow up period of 6 month. More marginal deterioration was observed after 12 months follow up.

CELTRA DUO was introduced to offer a stronger glass ceramic material thanks to its zirconia reinforcement (approx. $10 \%$ by weight) that could undergo phase transformation of the tetragonal phase to the monoclinic phase with a volume increase thus prevents crack propagation which might lead to a better clinical performance in terms of fracture. Also, it has Optimized edge stability compared to leucite-based ceramics that might result in better marginal adaptation, retention and less post-operative sensitivity [8].

The aim of this study was to evaluate the clinical performance of IPS Empress CAD versus Polished Celtra Duo ceramic laminate veneers.

The null hypothesis of this study was that, for anterior teeth requiring conservative labial restoration, veneers constructed using Polished Zirconia reinforced Lithium silicate ceramics (Celtra Duo) compared to IPS Empress CAD ceramics will provide better fracture resistance, marginal integrity and survival rate.

\section{MATERIAL AND METHODS}

\section{Ethical considerations and approval}

This study was reviewed by the Ethics Committee of Scientific Research - Faculty of Dentistry - Cairo University, Cairo, Egypt and 
approved in July 2017 (approval no. 17711). A written informed consent was obtained from all patients who participated in the study under the approval of ethics committee.

\section{Registration}

This study was registered on the ClinicalTrials.gov (Identifier: NCT03136276)

\section{Study design}

This study was a double blind randomized controlled clinical trial with a 1:1 allocation ratio.

\section{Participants}

All patients selected for the study were with an age range between 20 to 30 years old, have no active periodontal or pulpal diseases, have teeth with good restorations. Their chief complaint was to enhance their smile. Information was given to each patient regarding the alternative treatment options. The treatment plan was explained for each patient. Then, they agreed to sign the informed consent before proceeding to clinical work. They were able and willing to maintain good oral hygiene measures. All participants were recruited during the time from September 2017 till November 2018 from the outpatient clinic of Fixed Prosthodontics Department, Faculty of Dentistry, Cairo University, Cairo, Egypt. Screenings of patients were carried out until target number was reached. This study was completed by January 2020. Full medical and dental history were obtained from all participants.

\section{Sample size calculation}

Based on previous studies by Beier et al. [6] and Zimmermann et al. [10], a total sample size of 36 laminate veneers (18 in each of the 2 groups) will have $82 \%$ power to detect a difference in percentage of fracture of $13.7 \%$; the percentage of fracture when using leucite based porcelain laminate veneers is $17 \%$ and $3.3 \%$ when using zirconia-reinforced lithium silicate ceramic with a 0.05 two-sided significance level (90\% confidence interval). Sample size was calculated using nQuery Advisor.

\section{Allocation concealment}

A prosthodontics colleague who was at arm's length from the study was asked to generate the random sequence of participant allocation. This process was completed electronically, using computer-based generation programs. This person prepared sequentially numbered opaque envelops, each of which contained a card that was marked with the group assignment (A or B) according to the randomly generated sequence. When the recruitment process started and the consenting participant was deemed eligible to participate in the RCT, the next sealed envelope in the sequence was opened and the participant was assigned to the study group indicated on the card.

\section{Implementation}

The candidate under supervision was responsible of all procedures, patient selection, preparation, shade selection, try in and bonding.

\section{Allocation}

\section{Sequence generation}

A prosthodontics colleague allocated the participant patients into two groups with 1:1 allocation ratio by using computerized Sequence generation

\section{Randomization Sequence Generator}

Participants were allocating in two different groups with 1:1 allocation ratio by using computerized sequence generation (www. randomizer.org).

\section{Participants were assigned in two groups:}

Group (I) control group ( $n=18)$ : included patients received IPS Empress Cad laminate veneers with butt preparation design.

Group (II) intervention group ( $\mathrm{n}=18)$ : included patients received CELTRA DUO laminate veneers with butt preparation design.

\section{Blinding}

Double blinding (trial participants and outcome assessor), Prosthodontics colleague assessors who are blinded about the aim of the study and participant's allocation were responsible for assessing the outcomes of this study. The level of intra- and inter-examiner reliability was determined for each assessor by the performance of a calibration session prior to the start of the trial. A training exercise to the assessors with the main investigator helped to standardize measurement 
techniques and parameters. An interactive calibration session will enable the investigator to quantitate the measurement variability among and between assessors and enable the optimization of the measurement process. The assisstant supervisor (Jylan El Guindy) solved any conflict that may arise between the assessors by repeating the assessing and giving the final opinion.

Pre-operative photographs for each patient were taken using $100 \mathrm{~mm}$ usm Canon macro lens mounted on Canon 650D DSLR camera (Canon, Japan) (Figure 1). Two pairs of alginate impressions (Tropicalgin, Zhermack, Italy) for upper and lower arches were taken using stock trays, poured with type IV dental stone (DenfloHX, Prevest DenPro, India). One pair of impression was used for making diagnostic cast and the other for the study cast. The diagnostic casts were mounted on a semi adjustable articulator to assess horizontal and vertical overlap (overjet and overbite) between maxillary and mandibular incisors in order to preserve the anterior guidance. Following careful analysis of the diagnostic models, minimal veneer preparation was performed for the teeth to be restored with veneers. Diagnostic wax up was fabricated on diagnostic model in order to establish the appropriate tooth proportion, incisal edge positions, correction of minor tooth rotations and measuring the spaces in the hope of creating a more natural appearance.

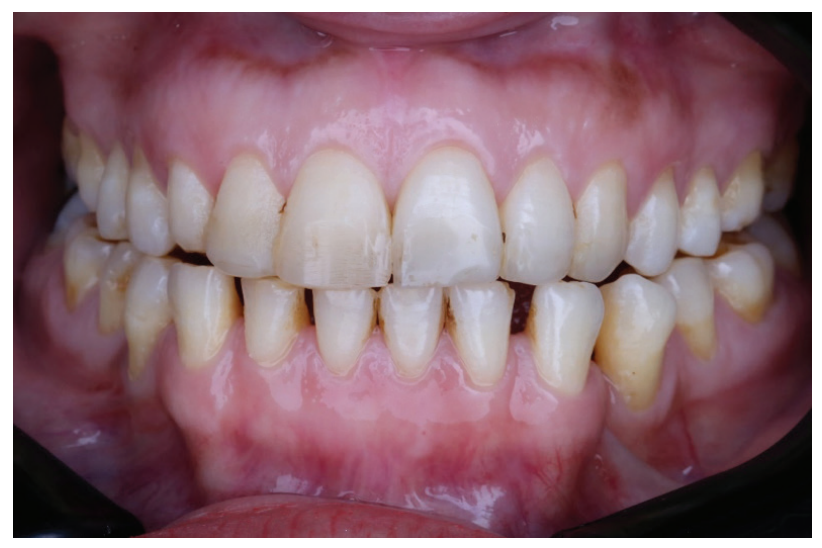

Figure 1 - Intraoral frontal view.

A putty silicon (ZitaPlus, Zhermack, Italy) was used to obtain index for each patient using condensation silicon impression material. Each index was vertically cut at the mid of central, lateral, and canine of each side to assess the amount of preparation of incisal and labial surfaces respectively. Another putty silicon index was fabricated on the diagnostic wax up model which was used later for temporization.

The labial reduction was started with horizontal orientation grooves using depth cutter wheels (Universal crown and veneer preparation set, Intensiv, Switzerland) in order to accommodate veneers of equal thickness. Final depth of the preparation was marked and accentuated with a pencil. Then the remaining island of the enamel was removed till the depth of original grooves to uniformly reduce the labial surface using a tapered diamond stone with around end of $0.5 \mathrm{~mm}$ diameter. Labial reduction was $0.3 \mathrm{~mm}$ at the cervical third and $0.5 \mathrm{~mm}$ at the middle and incisal thirds to ensure even preparation thickness. The preparation was carried out in two different planes following the contour of the labial surface. Then the preparation was verified with the silicon index to check the amount of labial preparation. Vertical orientation grooves were done on the incisal edge of the tooth ensuring not to penetrate more than the diameter of the stone visually. The tapered stone with round end diamond stone was placed parallel to the incisal edge to remove the projection between grooves resulting in $1 \mathrm{~mm}$ butt joint incisal preparation. Teeth were finished and smoothed with $1 \mathrm{~mm}$ incisal reduction (Butt joint preparation design). Then each preparation was verified vertically with the silicone index to check the amount of incisal reduction. The cervical margin was created supra-gingivally along the free gingival margin. The margin of the preparation was ended by a chamfer finish line $0.5 \mathrm{~mm}$ diameter using a tapered diamond stone with a round end. Due to using CAD CAM system in all restorations the interproximal preparation not extended beyond the contact areas except in spacing cases. The preparation was done using a tapered diamond stone with a round end.

All sharp line angles that might serve as a focal point for stress concentration were rounded using tapered round end diamond stone particularly at the junction of the incisal angle to both the labial and proximal surfaces. 
Before proceeding with the following steps, a retraction cord was used to allow accurate impression making (Figure 2).

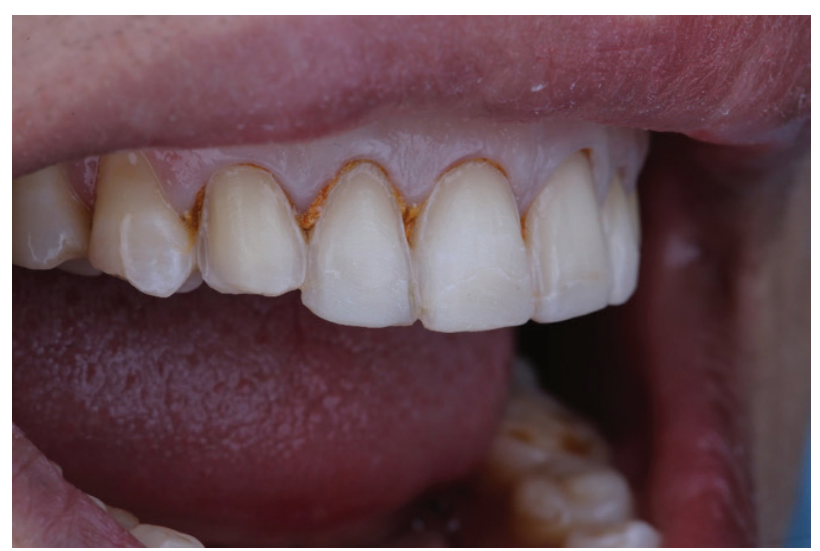

Figure 2 - Preparation after finishing

Final impression was taken using addition silicon (Elite HD+, Zhermack, Italy) in stock trays. Two step impression technique was done, first putty viscosity was taken then light viscosity was applied. Application of light using automatic mixing tips and dispensing with impression gun which produced complete homogenous mix.

The silicon index that was fabricated on the waxed-up cast was used for provisional restoration (Structure 2SC, Voco, USA) construction. The patient viewed the results of the provisionals and any modifications were discussed with the operator.

Once the dental laboratory received the final impression, master casts were poured with a type IV dental stone according to manufacturer's instruction, with respect to water/powder ratio and mixing time. Vacuum mixing was used for proper mixing to ensure the production of void free casts. An extra oral scanner (Ceramill Map 400 Scanner, Amann Girrbach GmbH, Austria) was used to scan the master cast. A threedimensional image was obtained for each tooth on the computer screen. Using Exocad software (Exocad GmbH, Germany), then the captured pictures were saved in the preparation folder. The software calculated a virtual model from the scanned pictures and an automatic margin finder was used for preparation margin detection. The cement space was set by the software to be 50 microns (Figure 3 ). Using 5 -axis milling machine (Ceramill Motion II, Amann Girrbach $\mathrm{GmbH}$, Austria) the veneers were milled from IPS Empress CAD (Ivoclar Vivadent, Germany) and CELTRA DUO (Dentsply Sirona, Germany) blocks. The milling process started as follows: the type of block (IPS Empress CAD - CELTRA DUO) as well as the size were selected and placed in the spindle of the milling chamber and fastened with set screw. The milling process was completed without any interference with one diamond bur in the shaping process, with copious water sprayed from both directions. After completing the milling process, the veneers were separated manually from the block holder with a diamond cutting instruments.

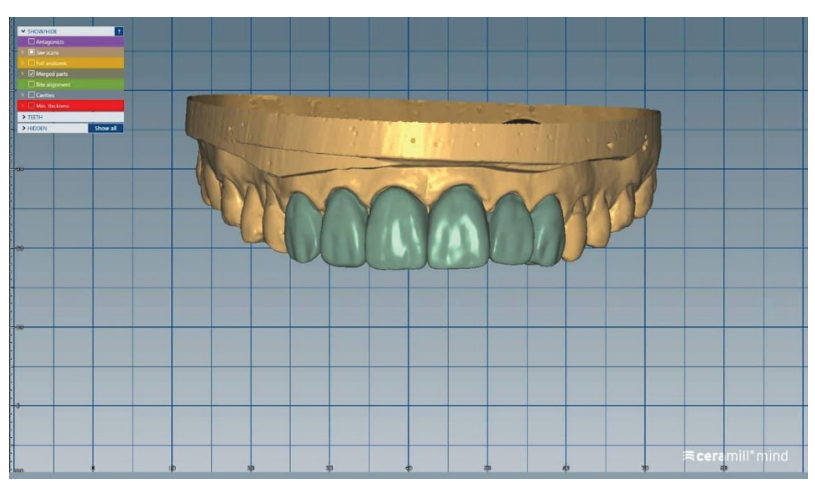

Figure 3 - Designing of the laminate veneers frontal view.

According to the manufacturer instructions, a universal contouring \& polishing kit (Meisinger, USA) was used. A coarse grit finishing instrument was used to prepare the surface for polishing and to create a more uniform surface. Followed by a medium and then a fine wheel was used at $(8,000$ $12,000 \mathrm{rpm}$ ) using light to medium pressure.

After veneers have been tried in, they were cleaned with alcohol, rinsed with water and then the following regime for preparing the fitting surface of the veneers was carried out. The fitting surface of the ceramic veneers were etched for 60 seconds in case of IPS Empress veneers and for 30 seconds in case of Celtra Duo veneers using 9.5\% hydrofluoric acid. The veneers were rinsed with water for 20 seconds then dried with air by using three-way syringe. Following this protocol, the veneers surfaces appeared clean and had a similar appearance to etched enamel. A single coat of the ceramic primer was then applied to the bonding 
surface of the veneers and left for 1 minute then air dried.

For preparation of tooth for bonding, 37\% Phosphoric acid etchant was applied to enamel for 30 seconds. And then rinsed and dried until enamel appeared frosty. Finally, surfaces were dried gently for 5 seconds. A fully saturated brush tip of Single bond 2 (3M ESPE, Germany) was used to apply two coats of adhesive. Luting resin cement (Choice2 light-cured Cements, Bisco, U.S. A) was applied to the tooth and fitting surfaces of the veneers using a mini brush. The veneers were placed to the teeth in position from the midline starting from the midline and moving laterally. Excess cement was removed using sharp explorer after 2 seconds of preliminary light polymerization and the veneers were then completely light polymerized for at least 60 seconds from each aspect of the tooth. A waxed dental floss was used inter dentally for complete removal of excess cement in between veneers, and articulating paper was used to check for any occlusal interferences after complete curing (Figure 4).

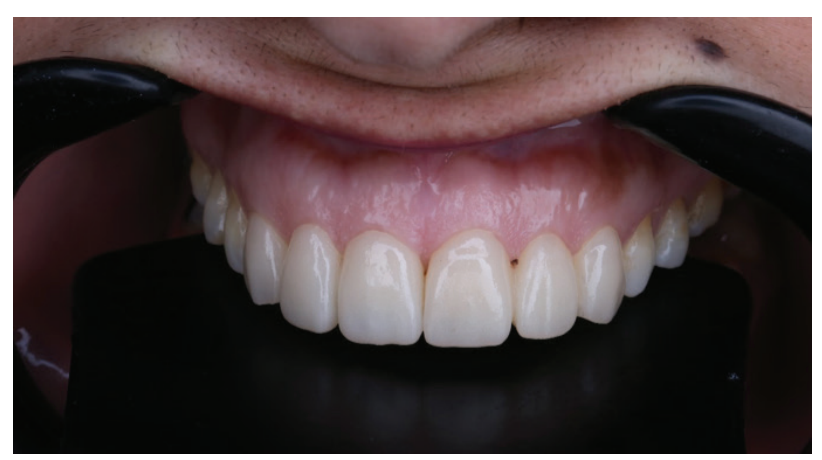

Figure 4 - Postoperative intraoral frontal view.

Patients were instructed to perform brushing and flossing regularly and to use nonabrasive fluoridated tooth paste. They were informed to avoid the excessive stresses, avoid bite on fingernails. The patients returned to the clinic after 1 week to permit a final examination of aesthetics, phonetics and occlusion. Follow up sessions were done every two months for each patient using dental probe and operator vision to evaluate the fracture, survival rate, marginal adaptation, sensitivity and caries. Follow up done according to USPHS grades (United States Public Health Service) (Table I).
Table I - The different outcomes and their measuring device and measuring unit

\begin{tabular}{|c|c|c|c|}
\hline & $\begin{array}{l}\text { outcome } \\
\text { name }\end{array}$ & $\begin{array}{l}\text { Measuring } \\
\text { device }\end{array}$ & Measuring Unit \\
\hline $\begin{array}{c}\text { Primary } \\
\text { 1ry }\end{array}$ & Fracture & $(\mathrm{USPHS})^{1}$ & $\begin{array}{c}\text { Ono fracture } \\
1 \text { minor cracks line over the restoration } \\
2 \text { minor chipping of the restoration (1/4) } \\
3 \text { moderate chipping of the restoration (1/2) } \\
4 \text { sever chipping of the restoration } \\
5 \text { complete fracture }\end{array}$ \\
\hline \multirow{4}{*}{$\begin{array}{c}\text { Secon- } \\
\text { dary } \\
2 \text { ry }\end{array}$} & $\begin{array}{l}\text { Survival } \\
\text { rate }\end{array}$ & (USPHS) & $\begin{array}{c}\text { Oretained } \\
1 \text { debonded }\end{array}$ \\
\hline & sensitivity & (USPHS) & $\begin{array}{c}\text { 0 no sensitivity } \\
1 \text { slight sensitivity } \\
2 \text { moderate sensitivity } \\
3 \text { sever sensitivity }\end{array}$ \\
\hline & $\begin{array}{l}\text { Marginal } \\
\text { adaptation }\end{array}$ & (USPHS) & $\begin{array}{c}0=\text { smooth margin } \\
1=\text { enamel exposed } \\
2=\text { base or dentin exposed } \\
3=\text { debonding from one end } \\
4=\text { debonding from both ends }\end{array}$ \\
\hline & caries & (USPHS) & $\begin{array}{l}0=\text { no evidence of caries at the margin of } \\
\text { restoration } \\
1=\text { evidence of caries continuous with the } \\
\text { margin of restoration }\end{array}$ \\
\hline
\end{tabular}

\section{RESULTS} (Table II).

Descriptive statistical analysis presented in

\section{Fracture} evaluation:

According to USPHS criteria for fracture

\section{a) Group I (IPS Empress):}

There was no statistically significant difference between (Base line), (After 2 months), (After 4 months), (After 6 months), (After 8 months), (After10 months) and (After 12 months) where $(\mathrm{p}=1)$.

Zero score was recorded for all the veneers at all the intervals of evaluation.

\section{b) Group II (Celtra Duo polished):}

There was no statistically significant difference between (Base line), (After 2 months), (After 4 months), (After 6 months), (After 8 months), (After10 months) and (After 12 months) where $(p=1)$.

Zero score was recorded for all the veneers at all the intervals of evaluation.

\section{Relation between both groups:}

There was no statistically significant difference between (Group I) and (Group II) both groups showed zero scoring in all time periods. 
Table I - Descriptive statistical analysis of the outcomes

\begin{tabular}{|c|c|c|c|c|c|c|c|c|c|c|c|c|c|c|c|}
\hline \multirow{2}{*}{\multicolumn{2}{|c|}{$\begin{array}{l}\text { Modified USPHS } \\
\text { criteria }\end{array}$}} & \multicolumn{2}{|c|}{ Base line } & \multicolumn{2}{|c|}{ After 2 months } & \multicolumn{2}{|c|}{ After 4 months } & \multicolumn{2}{|c|}{ After 6 months } & \multicolumn{2}{|c|}{ After 8 months } & \multicolumn{2}{|c|}{ After 10 months } & \multicolumn{2}{|c|}{ After 12 months } \\
\hline & & $\begin{array}{c}\text { Empress } \\
(n=18)\end{array}$ & $\begin{array}{l}\text { Celtra } \\
(n=18)\end{array}$ & $\begin{array}{c}\text { Empress } \\
(n=18)\end{array}$ & $\begin{array}{l}\text { Celtra } \\
(n=18)\end{array}$ & $\begin{array}{c}\text { Empress } \\
(n=18)\end{array}$ & $\begin{array}{l}\text { Celtra } \\
(n=18)\end{array}$ & $\begin{array}{c}\text { Empress } \\
(n=18)\end{array}$ & $\begin{array}{l}\text { Celtra } \\
(n=18)\end{array}$ & $\begin{array}{c}\text { Empress } \\
(n=18)\end{array}$ & $\begin{array}{l}\text { Celtra } \\
(n=18)\end{array}$ & $\begin{array}{c}\text { Empress } \\
(n=18)\end{array}$ & $\begin{array}{l}\text { Celtra } \\
(n=18)\end{array}$ & $\begin{array}{c}\text { Empress } \\
(n=18)\end{array}$ & $\begin{array}{l}\text { Celtra } \\
(n=18)\end{array}$ \\
\hline \multirow{6}{*}{ Fracture } & 0 & 18 & 18 & 18 & 18 & 18 & 18 & 18 & 18 & 18 & 18 & 18 & 18 & 18 & 18 \\
\hline & 1 & 0 & 0 & 0 & 0 & 0 & 0 & 0 & 0 & 0 & 0 & 0 & 0 & 0 & 0 \\
\hline & 2 & 0 & 0 & 0 & 0 & 0 & 0 & 0 & 0 & 0 & 0 & 0 & 0 & 0 & 0 \\
\hline & 3 & 0 & 0 & 0 & 0 & 0 & 0 & 0 & 0 & 0 & 0 & 0 & 0 & 0 & 0 \\
\hline & 4 & 0 & 0 & 0 & 0 & 0 & 0 & 0 & 0 & 0 & 0 & 0 & 0 & 0 & 0 \\
\hline & 5 & 0 & 0 & 0 & 0 & 0 & 0 & 0 & 0 & 0 & 0 & 0 & 0 & 0 & 0 \\
\hline \multirow{2}{*}{ Survival rate } & 0 & 18 & 18 & 18 & 18 & 18 & 18 & 18 & 18 & 18 & 18 & 18 & 18 & 18 & 18 \\
\hline & 1 & 0 & 0 & 0 & 0 & 0 & 0 & 0 & 0 & 0 & 0 & 0 & 0 & 0 & 0 \\
\hline \multirow{4}{*}{ Sensitivity } & 0 & 18 & 18 & 18 & 18 & 18 & 18 & 18 & 18 & 18 & 18 & 18 & 18 & 18 & 18 \\
\hline & 1 & 0 & 0 & 0 & 0 & 0 & 0 & 0 & 0 & 0 & 0 & 0 & 0 & 0 & 0 \\
\hline & 2 & 0 & 0 & 0 & 0 & 0 & 0 & 0 & 0 & 0 & 0 & 0 & 0 & 0 & 0 \\
\hline & 3 & 0 & 0 & 0 & 0 & 0 & 0 & 0 & 0 & 0 & 0 & 0 & 0 & 0 & 0 \\
\hline \multirow{5}{*}{$\begin{array}{l}\text { Marginal } \\
\text { adaptation }\end{array}$} & 0 & 18 & 18 & 18 & 18 & 18 & 18 & 18 & 18 & 18 & 18 & 18 & 18 & 18 & 18 \\
\hline & 1 & 0 & 0 & 0 & 0 & 0 & 0 & 0 & 0 & 0 & 0 & 0 & 0 & 0 & 0 \\
\hline & 2 & 0 & 0 & 0 & 0 & 0 & 0 & 0 & 0 & 0 & 0 & 0 & 0 & 0 & 0 \\
\hline & 3 & 0 & 0 & 0 & 0 & 0 & 0 & 0 & 0 & 0 & 0 & 0 & 0 & 0 & 0 \\
\hline & 4 & 0 & 0 & 0 & 0 & 0 & 0 & 0 & 0 & 0 & 0 & 0 & 0 & 0 & 0 \\
\hline \multirow{2}{*}{ Caries } & 0 & 18 & 18 & 18 & 18 & 18 & 18 & 18 & 18 & 18 & 18 & 18 & 18 & 18 & 18 \\
\hline & 1 & 0 & 0 & 0 & 0 & 0 & 0 & 0 & 0 & 0 & 0 & 0 & 0 & 0 & 0 \\
\hline
\end{tabular}

\section{Survival rate}

According to USPHS criteria for survival rate evaluation:

\section{a) Group I (IPS Empress):}

There was no statistically significant difference between (Base line), (After 2 months), (After 4 months), (After 6 months), (After 8 months), (After10 months) and (After 12 months) where $(p=1)$.

Zero score was recorded for all the veneers at all the intervals of evaluation.

\section{b) Group II (Celtra Duo polished):}

There was no statistically significant difference between (Base line), (After 2 months), (After 4 months), (After 6 months), (After 8 months), (After10 months) and (After 12 months) where $(p=1)$.

Zero score was recorded for all the veneers at all the intervals of evaluation.

\section{Relation between both groups}

There was no statistically significant difference between (Group I) and (Group II) both groups showed zero scoring in all time periods.

\section{Sensitivity} evaluation:

According to USPHS criteria for sensitivity

\section{a) Group I (IPS Empress):}

There was no statistically significant difference between (Base line), (After 2 months), (After 4 months), (After 6 months), (After 8 months), (After10 months) and (After 12 months) where $(p=1)$.

Zero score was recorded for all the veneers at all the intervals of evaluation.

\section{b) Group II (Celtra Duo polished):}

There was no statistically significant 
difference between (Base line), (After 2 months), (After 4 months), (After 6 months), (After 8 months), (After10 months) and (After 12 months) where $(p=1)$.

Zero score was recorded for all the veneers at all the intervals of evaluation.

\section{Relation between both groups}

There was no statistically significant difference between (Group I) and (Group II) both groups showed zero scoring in all time periods.

\section{Marginal adaptation}

According to USPHS criteria for marginal adaptation evaluation:

\section{a) Group I (IPS Empress):}

There was no statistically significant difference between (Base line), (After 2 months), (After 4 months), (After 6 months), (After 8 months), (After10 months) and (After 12 months) where $(\mathrm{p}=1)$.

Zero grade was recorded for all the veneers at all the intervals of evaluation.

\section{b) Group II (Celtra Duo polished):}

There was no statistically significant difference between (Base line), (After 2 months), (After 4 months), (After 6 months), (After 8 months), (After10 months) and (After 12 months) where $(\mathrm{p}=1)$.

Zero grade was recorded for all the veneers at all the intervals of evaluation.

\section{Relation between both groups}

There was no statistically significant difference between (Group I) and (Group II) both groups showed (100\%) Zero grading in all time periods.

\section{Caries}

According to USPHS criteria for caries evaluation:

\section{a) Group I (IPS Empress):}

There was no statistically significant difference between (Base line), (After 2 months), (After 4 months), (After 6 months), (After 8 months), (After10 months) and (After 12 months) where $(\mathrm{p}=1)$.

Zero grade was recorded for all the veneers at all the intervals of evaluation.

\section{b) Group II (Celtra Duo polished):}

There was no statistically significant difference between (Base line), (After 2 months), (After 4 months), (After 6 months), (After 8 months), (After10 months) and (After 12 months) where $(p=1)$.

Zero grade was recorded for all the veneers at all the intervals of evaluation.

\section{Relation between both groups}

There was no statistically significant difference between (Group I) and (Group II) both groups showed (100\%) Zero grading in all time periods.

\section{DISCUSSION}

For clinically successful dental restorations, four distinct properties should be existing: marginal adaptation, biocompatibility, esthetics and mechanical strength [11].

In the present study all teeth included were anterior teeth. It was restricted to noncarious, unrestored teeth which prevented the size and sites of disease or restorations from influencing the preparations carried out.

In the present study preparation design for all teeth was with chamfer finish line labially, interproximal extension and butt joint incisally. The finish line was located supragingivally $[12,13]$.

Hahn et al. [14] reported that butt-joint preparation showed better stress distribution 
to the tooth body, suggesting that the forces had to be sustained to a greater extent by the veneer itself. Butt joint incisal configuration still permits the preservation of peripheral enamel layer around all margins. This was in agreement with Mirra et al. [15] who measured fracture strength and microleakage of laminate veneers with different designs and found the highest fracture load in teeth prepared with $2 \mathrm{~mm}$ incisal reduction without palatal chamfer.

In this study ceramic laminate veneers were fabricated from two different ceramics materials: IPS Empress CAD is a leucite glassceramic of the $\mathrm{SiO}_{2}-\mathrm{Al}_{2}-\mathrm{O}_{3}-\mathrm{K}_{2} \mathrm{O}$ material systems with leucite crystal ranging from 5 to $10 \mu \mathrm{m}$ in size. The leucite crystals responsible for increasing the material strength and inhibition of crack propagation, while the crystalline phase absorbs the fracture energy. Resistance and flexural strength of the material is improved duo to the difference in the coefficient of thermal expansion between the glass phase and the crystalline phase, as well as the cooling process following sintering phase (160 Mpa) [7].

CELTRA DUO: is a new generation of glass ceramic material enriched with approximately $10 \%$ zirconia by weight, which resulting in zirconia reinforced lithium silicate ceramic (ZLS). The material has a special fine grained and homogeneous structure which provides excellent material quality and consistency, higher load capacity as well as long term reliability. Additionally, the material has outstanding processing characteristics, including easy milling and polishing. After the milling process takes place no additional crystallization step required [7]. The flexural strength of the milled restoration is $210 \mathrm{MPa}$. After glaze firing the flexural strength is increased to $370 \mathrm{MPa}$ [8].

\section{Fracture results}

The most common failure type for laminate veneers was reported to be fractures.
Different factors are responsible for crack development in all-ceramic restorations of all forms. The greatest shortcoming of ceramic materials is their low ductility that is inherent problem yielding to crack formation. Also, polymerization shrinkage of the luting resin cements may create stress concentrations at the adhesive interface. In-vivo strength degradation of restorations based on dental ceramics may occur in oral environment as a consequence of masticatory and parafunctional forces more than $200 \mathrm{~N}[3,4,5,6]$.

Flaws of different magnitudes may be introduced to the restorations depending on the chewed food and associated mastication force. In addition, damage may occur during the adjustments of ceramic restorations by the technician or the clinician prior to or during their placement in the mouth [16].

In this study, Zero score was recorded for all veneers during all the follow- up sessions. Additionally, there was no statistically significant difference between the two groups.

It was found by Mirra et al [15] that butt joint design with $2 \mathrm{~mm}$ incisal preparation presented the highest fracture resistance and least microleakage of laminate veneers with different designs.

Also, zirconia-reinforced lithium silicate ceramic is a glass ceramic material enriched with a zirconium dioxide content around ten times that of traditional CAD/CAM glass ceramic. Zirconia is known for phase transformation of the tetragonal phase to the monoclinic phase with a volume increase that prevents crack propagation [17] in combination with a particularly finegrained and homogeneous structure leads to a high fracture strength of $370 \mathrm{MPa}[18,19,20]$

The results of this study were in agreement with Osman et al [21] who evaluated the clinical performance of VITA Suprinity versus IPS E-Max CAD ceramic laminate veneers where both groups showed 100\% Alpha score after 1 year 
follow up.

\section{Survival rate results}

Zero score of retention was recorded for all veneers. Etching the ceramic surface with 9.5\% HF increased the surface area and facilitated the penetration and retention of resin cement into the microretentions of the treated surface. the bonding process can be enhanced by application of silane coupling agent. These agents are capable of forming chemical bonds between the inorganic phase of the ceramic and the organic phase of the resin that will increase bonding strength to ceramic laminate veneers itself thus improve the durability of the adhesive interface overtime $[22,23]$.

\section{Post-operative sensitivity results}

The result of this clinical study showed that in both material post-operative sensitivity was graded Zero during all follow up session graded. Additionally, there is no significant difference between the two materials. This may be related to the extension of preparation which mainly in enamel in our study. This was in agreement with Öztürk et al [2] who show that postoperative sensitivity when preparation done in enamel or enamel with minimal dentin evaluation was Alpha during two years follow up.

This also conducted with Karagözoğlu et al [22] when they found that laminate veneers have $100 \%$ successes in post-operative sensitivity after 2 years follow up.

\section{Marginal adaptation results}

Taskonak et al. [24] examined the "perfect margin" and defined it as two adjoining surfaces (cement-ceramic, cement-tooth), which have no interruption of the continuous margin and merge into each other without any difference in level. The "perfect margins" can be analyzed by measuring the marginal gaps.

Marginal fit is considered one of the most important criteria in the evaluation of fixed dental prostheses and is one of the most significant prerequisites for the long- term success of ceramic restorations. The large the marginal discrepancy results in the high plaque index with subsequent gingival inflammation and more the exposure of luting material to the oral environment. Furthermore, if the cement seal fails, it allows bacterial percolation, secondary caries, pulpal inflammation, and eventually pulpal necrosis could result [25].

Some studies have reported that the ideal marginal gap should be 25 to $50 \mu \mathrm{m}$ for cemented restorations. Other studies considered the marginal gap values of $100-150 \mu \mathrm{m}$ to be clinically acceptable for cemented restorations. Recent studies have considered the clinically acceptable values of marginal gap to be less than $100 \mu \mathrm{m}$ [26].

Measurement of marginal discrepancy should be consistent, reproducible, and standardized. There are many methods for measuring marginal discrepancy includes: (1) direct view, (2) tactile and visual examination which was conducted in this study $[26,27]$.

Good adaptation has been found to be critical for the longevity of restoration. In the literature the clinically acceptable size of marginal gap varies. For CAD/CAM fabricated restorations, the values reported in the literature before cementation range from 50 to $60 \mu \mathrm{m}$. Guess et al. [28] reported that CAD/CAM manufactured restorations exhibited significantly larger internal fit values than the press groups. While Aboushelib et al [29] reported that pressable ceramic laminate veneers produced higher marginal adaptation, homogenous and thinner cement film thickness, and improved resistance to microleakage compared to machinable ceramic veneers.

Placement of restoration margins $1 \mathrm{~mm}$ supra-gingival within enamel, may explain the absence of marginal deterioration in these 
areas. It is well known that the adhesive bond in enamel is more durable than that in dentine [28]. In this study the extension of preparation was mainly in enamel.

The results obtained in the present study as zero score for marginal adaptation were attributed to the butt-joint incisal configuration and preservation of a peripheral enamel layer around all margins, also, this design established an easy path of insertion of the laminate during bonding [30]. Najim et al. [31] found that the CAD/CAM veneers with butt joint incisal reduction produced the most accurate margins while the least favorable combination was the pressable ceramic veneers with overlapped incisal reduction.

In addition, resin cement used effectively reduces microleakage. This may be attributed to formation of a hybrid layer with excellent quality at the dentine, ensuring adhesion and resistance to various stresses [18]. In 2009 Aykor et al. [32] found that using total-etch system for bonding ceramic laminate veneers resulted in successful marginal adaptation and detection of no secondary caries. This is due to the fact that the boundaries of the veneer preparation were left within enamel in all cases.

\section{Caries results}

The result of this clinical study showed that in both material secondary caries was graded Zero during all follow up sessions. Additionally, there is no significant difference between the two materials. This was in agreement with Guess et al [28], D'arcangelo et al. [33] who showed that secondary caries when preparation done in enamel evaluation was Alpha during follow up period.

Finally, the hypothesis was rejected as both materials were graded Zero during all follow up sessions and no significance difference found between the two materials (IPS Empress CAD - Celtra Duo).
The limitation of this study was the short follow up period where the clinical outcomes of laminate veneers could be adversely affected with longer follow up time. Further studies with longer follow up period and larger number of participants is suggested.

\section{CONCLUSION}

Within limitations of this study, the following conclusion could be drawn as follows:

Both IPS Empress Cad and Polished Celtra Duo laminate veneers revealed accepted successful clinical performance in terms of fracture resistance, marginal adaptation, retention, and sensitivity after one year follow up.

\section{Acknowledgments}

The authors are grateful to the staff members of Fixed Prosthodontic Department, Faculty of Dentistry, Cairo University for content contributions, their critical review of the manuscript and support during the development and writing of this manuscript.

\section{Funding}

This study was self-funded .

\section{Conflict of interest}

The authors have no proprietary, financial, or other personal interest of any nature or kind in any product, service, and/or company that is presented in this article.

\section{Regulatory Statement}

This study was conducted in accordance with all the provisions of the local human subject's oversight committee guidelines and policies of: the Ethics Committee of Scientific Research - Faculty of Dentistry - Cairo University. The approval code for this study is: 17711 . 


\section{REFERENCES}

1. Shetty A, Kaiwar A, Shubhashini N,Ashwini P,Naveen D, AdarshaM, Shetty M, Meena N. Survival rates of porcelain laminate restoration based on different incisal preparation designs: An analysis. J Conserv Dent. 2011 Jan;14(1):10-5. doi: 10.4103/0972-0707.80723.PMID:21691498; PMCID: PMC3099105.

2. OztürkE,Bolay S. Survival of porcelain laminate veneers with different degrees of dentin exposure: 2-year clinical results. J Adhes Dent. 2014 0ct;16(5):481-9. doi:10.3290/j.jad.a32828.PMID:25279393.

3. Morimoto S, Albanesi RB, Sesma N, Agra CM, Braga MM. Main Clinical Outcomes of Feldspathic Porcelain and Glass-Ceramic Laminate Veneers: A Systematic Review and Meta-Analysis of Survival and Complication Rates. Int JProsthodont. 2016 Jan-Feb;29(1):38-49. doi: 10.11607/jp.4315. PMID: 26757327.

4. Obradović-Đuričić KB, Medić VB, Dodić SM, Đurišić SP, Jokić BM, Kuzmanović JM. Porcelain veneers-preparation design: A retrospective review. Hemijska industrija. 2014;68(2):179-92. doi: 10.2298/HEMIND1303230420

5. Gresnigt MM, Kalk W, Özcan M. Clinical longevity of ceramic laminate veneers bonded to teeth with and without existing composite restorations up to 40 months. Clin Oral Investig. 2013 Apr;17(3):823-32. do: 10.1007/s00784-0120790-5. Epub 2012 Jul 21. PMID:22821429.

6. Beier US, Kapferer I,Burtscher D, DumfahrtH. Clinical performance of porcelain laminate veneers for up to 20 years. Int J Prosthodont. 2012 JanFeb;25(1):79-85.PMID:22259802

7. Sannino G, GermanoF,Arcuri L, Bigelli E, ArcuriC, Barlattani A.CERECCAD/ CAM Chairside System. Oral Implantol (Rome). 2015 Apr 13;7(3):57-70. PMID: 25992260; PMCID:PMC4402686.

8. Rinke S, Pabel AK, Rödiger M,ZiebolzD. Chairside Fabrication of an All-Ceramic Partial Crown Using a Zirconia-Reinforced Lithium Silicate Ceramic. Case Rep Dent. 2016;2016:1354186. doi: 10.1155/2016/1354186. Epub 2016 Mar 6.PMID: 27042362;PMCID:PMC4799832

9. Flury S, Lussi A,Zimmerli B. Performance of different polishing techniques for direct CAD/CAM ceramic restorations. Oper Dent. 2010 Jul-Aug;35(4):470-81. doi: 10.2341/09-373-L.PMID:20672733.

10. Zimmermann M,Koller C, Mehl A, Hickel R. Indirect zirconia-reinforced lithium silicate ceramic CAD/CAM restorations: Preliminary clinical results after 12 months. Quintessence Int. 2017;48(1):19-25. doi: 10.3290/j.q.a37017.PMID: 27822572 .

11. Arif R, Dennison JB, Garcia D, Yaman P. Retrospective evaluation of the clinical performance and longevity of porcelain laminate veneers 7 to 14 years after cementation. J Prosthet Dent.2019 Jul;:22(1):31-37. doi:10.1016/j. prosdent.2018.09.007. Epub 2019 Mar 15. PMID:30885576.

12. Fradeani M, Redemagni M, Corrado M. Porcelain laminate veneers: 6- to 12-year clinical evaluation--a retrospective study. Int J Periodontics Restorative Dent. 2005Feb;25(1):9-17.PMID: 15736774.

13. Granell-Ruiz M, Fons-Font A, Labaig-Rueda C,Martínez-González A, RománRodríguez JL, Solá-Ruiz MF. A clinical longitudinal study 323 porcelain laminate veneers. Period of study from 3 to 11 years. Med Oral Patol Oral Cir Bucal. 2010 May 1;15(3):e531-7.doi:10.4317/medoral.15.e531. PMID:20038893.

14. Hahn P, Gustav M, Hellwig E. An in vitro assessment of the strength of porcelain veneers dependent on tooth preparation. J Oral Rehabil.2000 Dec;27(12):10249. doi:10.1046/j.1365-2842.2000.00640.x. PMID: 11251771.

15. Mirra A, El-Mahalawy S. Fracture strength and microleakage of laminate veneers. Cairo Dent J. 2009 May;25:245-54.

16. Coldea A, Swain MV, Thiel N. In-vitro strength degradation of dental ceramics and novel PICN material by sharp indentation. J Mech Behav Biomed Mater. 20130ct:26:34-42 doi:10.1016/.j.jmbbm.2013.05.004. Epub2013 May 15.PMID: 23807311.

17. Manicone PF, Rossi lommetti P,Raffaelli L. An overview of zirconia ceramics: basic properties and clinical applications. J Dent.2007 Nov;35(11):819-26. doi: 10.1016/j.jdent.2007.07.008. Epub2007 Sep 6.PMID:17825465.

18. Helvey G. The expansion of millable materials: new additions to the market increase patient care-options. Inside Dent Technol. 2014;5(4):58-71.

19. Preis $\mathrm{V}$, Behr M, Hahnel S, Rosentritt M. Influence of cementation on in vitro performance, marginal adaptation and fracture resistance of CAD/CAMfabricated ZLS molar crowns. Dent Mater. 2015 Nov;31(11):1363-9. doi:10.1016/j. dental.2015.08.154. Epub 2015 Sep 5.PMID:26345998.

20. Elsaka SE, Elnaghy AM. Mechanical properties of zirconia reinforced lithium silicate glass-ceramic. Dent Mater.2016 Jul;32(7):908-14. doi: 10.1016/j. dental.2016.03.013. Epub 2016 Apr 14. PMID:27087687.

21. Osman A, EL-Guindy J, Aboubakr K. Clinical evaluation of the fracture resistance for e-max cad and vita suprinity laminate veneers (randomized controlled clinical trial). EDJ. 2019 Jan;65(1):131-9.

22. Karagözoğlu I, Toksavul S, Toman M.3D quantification of clinical marginal and internal gap of porcelain laminate veneers with minimal and without tooth preparation and 2-year clinical evaluation. Quintessence Int 2016;47(6):461-71. doi:10.3290/j.qi.a35700.PMID:26949761.

23. Özdemir $\mathrm{H}$, Aladağ LI. Effect of different surface treatments on bond strength of different resin cements to lithium disilicate glass ceramic: an in vitro study. Biotechnology \& Biotechnological Equipment. 2017 Jul 4;31(4):815-20. doi: 10.1080/13102818.2017.1334589

24. Taskonak B, Anusavice KJ, Mecholsky JJ Jr. Role of investment interaction layer on strength and toughness of ceramic laminates. Dent Mater. 2004 Oct;20(8):701-8. doi: 10.1016/.jdental.2003.08.006.PMID: 15302450.

25. Hamza TA, Sherif RM. In vitro evaluation of marginal discrepancy of monolithic zirconia restorations fabricated with different CAD-CAM systems. JProsthet Dent 2017 Jun;117(6):762-766. doi: 10.1016/jprosdent.2016.09.011. Epub 2016 Nov 9.PMID:27836145.

26. Mounajed R,M Layton D, Azar B. The marginal fit of Emax Press and Emax CAD lithium disilicate restorations: A critical review. Dent Mater J.2016 Dec 1;35(6):835-844. doi:10.4012/dmj.2016-008. Epub 2016 Aug 20.PMID: 27546857.

27. Lin TM, Liu PR, Ramp LC, Essig ME, Givan DA, Pan YH. Fracture resistance and marginal discrepancy of porcelain laminate veneers influenced by preparation design and restorative material in vitro. J Dent 2012 Mar;40(3):202-9. doi: 10.1016/j.jdent2011.12.008. Epub 2011Dec 14.PMID:22198195.

28. Guess PC, Vagkopoulou T,Zhang Y, Wolkewitz M, Strub JR. Marginal and internal fit of heat pressed versus CAD/CAM fabricated all-ceramic onlays after exposure to thermo-mechanical fatigue. J Dent. 2014 Feb;42(2):199-209. do: 10.1016/j.jdent2013.10.002. Epub 20130ct24.PMID:24161516;PMCID: PMC4450820.

29. Aboushelib MN, Elmahy WA, Ghazy MH. Internal adaptation, marginal accuracy and microleakage of a pressable versus a machinable ceramic laminate veneers. JDent.2012 Aug;40(8):670-7.doi:10.1016/j.jdent.2012.04.019. Epub 2012Apr 27.PMID:22542500.

30. Naumova EA, Valta A, Schaper K, Arnold W, Piwowarczyk A. Microleakage of Different Self-Adhesive Materials for Lithium Disilicate CAD/CAM Crowns. Materials (Basel). 2015 Jun;8(6):3238-53. doi: 10.3390/ma8063238

31. Najim BA, Al-Rawill. The Influence of Different Fabrication Techniques and Preparation Designs on the Marginal Adaptation of Ceramic Veneers (An In vitro Comparative Study). JBaghdad College Dent. 2015;27(4):8-14. 
32 Aykor A OzelE Five-year clinical evaluation of 300 teeth restored with porcelain laminate veneers using total-etch and a modified self-etch adhesive system. Oper Dent. 2009 Sep-0ct;34(5):516-23. doi:10.2341/08-038-C. PMID: 19830964.
33. D'Arcangelo C,De Angelis F, Vadini M,D'Amario M. Clinical evaluation on porcelain laminate veneers bonded with light-cured composite: results up to 7 years. Clin Oral Investig.2012 Aug;16(4):1071-9. doi:101007/s00784-011-0593-0. Epub 2011 Jul 20.PMID:21773711.

\section{Hayat Ibrahim Mahrous EL-Banna}

(Corresponding address)

Faculty of Dentistry, Cairo University, Fixed Prosthodontics, Cairo, Egypt.

Date submitted: 2020 0ct 28

Email: hayat.dental.86@gmail.com 
